\title{
UMA QUESTÃO DE (IN)CIVILIDADE NO BRASIL MERIDIONAL: A IMIGRAÇÃO AÇORIANA NO RIO GRANDE DO SUL ATRAVÉS DA HISTORIOGRAFIA CLÁSSICA
}

\author{
A question of (in) civility in southern Brazil: the azoresian immigration in Rio Grande do Sul \\ through classic historiography
}

Una cuestión de (in) civilidad en el sur de Brasil: la inmigración azoresiana en Rio Grande do Sul a través de la historiografía clásica

\begin{abstract}
Daniel Luciano Gevehr, Doutor em História, Programa de Pós-graduaçāo em Desenvolvimento Regional (PPGDR), Faculdades Integradas de Taquara (FACCAT), Brasil. E-mail: danielgevehr@hotmail.com
\end{abstract}

\begin{abstract}
Resumo: O artigo analisa o papel desempenhado pelos imigrantes açorianos no Rio Grande do Sul a partir de alguns clássicos da historiografia rio-grandense, procurando identificar os "diferentes imigrantes" presentes nessas obras. Assim, analisamos as diferentes visões existentes sobre o açoriano na historiografia rio-grandense, preocupando-nos em não reconstituir a história deste processo imigratório, mas sim identificar, nas obras analisadas, o perfil construído por seus autores para esses imigrantes do século XVIII. Tendo como referencial o entendimento de que as obras sobre a imigração açoriana no RS se encontram em temporalidades e contextos distintos, é que passaremos a investigar essa rica produção, que ora os apresenta como sujeito grosseiro e rude; trabalhador e honesto, ora como construtor da identidade gaúcha.
\end{abstract}

Palavras-chave : Historiografia. Imigração Açoriana. Rio Grande do Sul.

Abstract: The article analyzes the role played by Azorean immigrants in Rio Grande do Sul based on some classics of Rio Grande do Sul historiography, seeking to identify the "different immigrants" present in these works. Thus, we analyze the different existing views on the Azorean in Rio Grande do Sul historiography, worrying about not reconstructing the history of this immigration process, but rather identifying, in the analyzed works, the profile built by its authors for these 18th century immigrants. Having as reference the understanding that the works on Azorean immigration in RS are in different temporalities and contexts, it is that we will start to investigate this rich production, which now presents them as a crude and rude subject; hardworking and honest, now as a builder of the gaucho identity.

Keywords: Historiography. Azorean immigration. Rio Grande do Sul 
Resumen: El artículo analiza el papel jugado por los inmigrantes azorianos en Rio Grande do Sul a partir de algunos clásicos de la historiografía de Rio Grande do Sul, buscando identificar los “diferentes inmigrantes" presentes en estos trabajos. Así, analizamos las diferentes visiones existentes sobre la historiografía azoriana en Rio Grande do Sul, cuidando no reconstruir la historia de este proceso migratorio, sino identificar, en las obras analizadas, el perfil construido por sus autores para estos inmigrantes del siglo XVIII. Teniendo como referencia el entendimiento de que los trabajos sobre la inmigración azoriana en RS se encuentran en diferentes temporalidades y contextos, es que comenzaremos a investigar esta rica producción, que ahora los presenta como un tema tosco y rudo; trabajador y honesto, ahora como constructor de la identidad gaucha.

Palabras clave: Historiografía. Inmigración azoriana. Río Grande del Sur.

\section{INTRODUÇÃO}

Diferente das demais regiões do Brasil, o Rio Grande do Sul, no extremo sul do país, nasceu espanhol, ou seja, suas terras estiveram durante praticamente 250 anos sob domínio da Coroa Espanhola. Assim, no contexto colonial da América Portuguesa, as preocupações com a ocupação do atual estado do RS, ocorrem muito mais tarde do que aconteceu no sudeste e no nordeste brasileiro. Todavia, não podemos esquecer que havia, aqui na América, as disputas por definição de fronteiras entre as Coroas de Espanha e de Portugal. Nesse contexto de conflito entre as duas Coroas é que se deu o início, ainda no século XVIII, do processo de povoamento do território rio-grandense.

Compreendida entre a Capitania de São Paulo e a Colônia de Sacramento, o RS era considerado um grande deserto demográfico, fazendo-se necessário dar início ao povoamento destas áreas, para defendê-las de possíveis ataques espanhóis que poderiam prejudicar os interesses lusos no Brasil meridional.

Enquanto que a área ao sul do Brasil encontrava-se à espera de povoadores, as ilhas da Madeira, Cabo Verde e Açores já estavam superpovoadas. Com o objetivo de solucionar este problema, seus habitantes fizeram representações ao Rei, pedindo que concedesse a graça de transportá-los para a América Portuguesa. Em 31 de agosto de 1746 publicou-se nas Ilhas o Edital, abrindo inscrições para os casais que desejassem migrar. Como garantias, o Rei oferecia algumas 
vantagens para os emigrantes, como custeio do transporte pela Fazenda Real, porém impunha uma restrição, os homens não poderiam ter mais de quarenta anos de idade e as mulheres mais de trinta anos de idade, além da obrigatoriedade de serem de religião católica.

O primeiro contingente de imigrantes açorianos deve ter chegado ao RS em 1752, no sítio de Viamão, onde se encontravam já instalados vários estancieiros. As condições em que se encontravam estes recém-chegados era bastante difícil, uma vez que não viram cumprir-se todas as promessas feitas pela Coroa, quando do Edital. Foi apenas em 1772 que as primeiras datas de terra foram distribuídas aos casais, com título legítimo.

A estância do Morro de Santana era o local adequado para o estabelecimento dos casais, uma vez que apresentava posição privilegiada em relação ao rio Guaíba e ao mar. Com este propósito a autoridade régia decidiu estabelecer um povoado açoriano neste local, desapropriando a estância de Ignácio Francisco, passando o local a se chamar Porto dos Casais e mais tarde Porto Alegre.

Estabelecidos, num primeiro momento nos campos de Viamão, a colonização açoriana dirigiu-se em direção aos rios Jacuí e firmaram-se nas margens do Guaíba, sendo as primeiras povoações as de Viamão, Vacaria, Santo Antônio da Patrulha, Mostardas e Estreito, avançando mais tarde para o interior do território, protegida com a guarnição de Santa Maria. Mais tarde foram fundadas as vilas de Nossa Senhora dos Anjos (Gravataí), as freguesias de Santana do Morro Grande de Viamão, Conceição da Serra (Osório), São Luís das Mostardas, Santo Amaro e São Nicolau do Jacuí (Cachoeira). Com essas ações oficiais, o RS teria sua primeira fase de povoamento realizada com êxito.

\section{OS AÇORIANOS NO RIO GRANDE DO SUL E A HISTORIOGRAFIA}

Em nossa análise selecionamos algumas obras que consideramos referenciais no estudo da imigração açoriana no RS. É a partir delas que procuramos entender as diferentes construções das 
representações historiográficas produzidas sobre os açorianos que se estabeleceram no RS. Com o objetivo de sistematizar de forma clara e objetiva nosso estudo, iremos organizá-lo a partir dos autores levantados, considerando-se também as respectivas datas de publicação, que por sua vez acabam por revelar o contexto ideológico e social em que cada produção se insere.

Iniciamos com a obra A Colonização Açoriana no Rio Grande do Sul ${ }^{1}$, de 1979, escrita por Wiederspahn. O autor afirma que o imigrante açoriano foi responsável por diversas transformações na estrutura fundiária e também na transformação social do atual RS. Chama a atenção para o fato de que os açorianos vieram para cá para formar a argamassa étnica sul-brasileira ${ }^{2}$, destacando-se assim que o açoriano veio a sobrepor-se às demais etnias que eram minoria nestas terras ao sul do Brasil, defendendo a ideia de que se a imigração não ocorreu perfeitamente como era esperado, esta não foi por culpa dos açorianos, mas sim pela morosidade das decisões da Coroa.

Evidencia-se na obra a integração que o açoriano realizava com os demais habitantes do sul, já que se apresentava em maior número, sendo que esta integração se dava ora por políticas de casamentos, negócios de compra e venda de mercadorias e todo tipo de relações sociais estabelecidas entre açorianos e os demais habitantes da região:

\footnotetext{
Mais numeroso e forte, demograficamente, que as demais correntes povoadoras de lagunistas, paulistas, portugueses reinóis ou madeirenses, fluminenses e até nordestinos, este coeficiente açoriano passou a integrar praticamente a quase totalidades das genealogias familiares sul-rio-grandenses. ${ }^{3}$
}

Observamos também que na sua obra é destacado o papel desempenhado pelos açorianos enquanto formadores da cultura sul-rio-grandense, sendo que, segundo o autor existe algo de açoriano em tudo o que nos apresenta como sendo tipicamente sul-rio-grandense.

\footnotetext{
${ }^{1}$ WIEDERSPAHN, Henrique Oscar. A Colonização Açoriana no Rio Grande do Sul. Porto Alegre: Escola Superior de Teologia São Lourenço de Brindes/ Instituto Cultural Português, 1979.

${ }^{2}$ Ibidem, p. 131.

${ }^{3}$ Ibidem, p. 133.
} 
Completando-se a esta ideia, o autor conclui que foram os açorianos aqueles que ainda uniram-se em benefício da luta pela defesa do território rio-grandense, sendo responsável também pela demarcação dos limites do território entre Portugal e Espanha durante o século XVIII:

Açorianos pacatos, paulistas audaciosos e precavidos e antigos moradores do nosso litoral, limitado pelos paredões da serra do Mar e de sua matas agrestes, conglomerando-se então como cavaleiros andantes e impetuosos em torno de seus chefes locais para, em cooperação com tropas de linha de outras regiões brasileiras, traçarem a golpes de lança e de espada nossas fronteiras meridionais definitivas, frente aos nossos antigos rivais e adversários daquela triste mas superada "corrida do Rio Grande". 4

Em seguida temos a obra História do Rio Grande do Sul $l^{5}$, publicada em 1985 e de autoria de Fidélis Dalcin Barbosa, que destaca como motivo da imigração açoriana no RS a necessidade urgente de povoar estas terras para garantir a posse efetiva e impossibilitar o avanço espanhol.

Barbosa chama a atenção pelo uso de adjetivos para referir-se aos açorianos e, portanto, acreditamos ser de fundamental relevância transcrevê-los aqui. Porém, devemos levar em consideração que a forma como Barbosa retrata os açorianos baseia-se na opinião de Souza Docca, e para tanto cita este autor:

Os açorianos formavam a elite do povo português, os elementos mais excelentes da península, pertencentes à nobreza portuguesa. Dotado de natural vivacidade, trabalhador, liberal, hospitaleiro, generoso, alegre, expansivo, morigerado, caritativo, vigoroso e sóbrio, inimigo da vida militar. ${ }^{6}$

Logo em seguida, cita novamente as ideias de Souza Docca para adjetivar os açorianos: As mulheres açorianas - continua o mesmo historiador - eram em geral belas, esbeltas, virtuosas, inteligentes, de olhos castanhos, de extrema vivacidade e de grande meiguice. ${ }^{7}$ De acordo com as ideias apresentadas acima, percebemos que Barbosa, ao referir-se aos açorianos tenta imprimir uma imagem positiva a respeito dos açorianos, recorrendo a palavras de forte significado.

\footnotetext{
${ }^{4}$ Ibidem, p. 134.

${ }^{5}$ BARBOSA, Fidélis Dalcin. História do Rio Grande do Sul. 3. ed. Porto Alegre: Escola Superior de Teologia São Lourenço de Brindes/Martins Livreiro Editora, 1985.

${ }^{6}$ Ibidem, p. 38.

${ }^{7}$ Ibidem, p. 38.
} 
Já o caráter trabalhador do imigrante açoriano é evidenciado na obra Açorianos e alemães no desenvolvimento da colonização e agricultura do Rio Grande do Sul ${ }^{8}$, de 1948 , de autoria de Dante de Laytano. Em seu estudo o autor refere-se aos habitantes provenientes das Ilhas como sendo os responsáveis pelo desenvolvimento inicial da atividade agrícola no RS, uma vez que, segundo Laytano, até então se praticava apenas a atividade pecuarista. Segundo ele, foram os açorianos que introduziram no RS a atividade agrícola, diversificando a economia da região que, até aquele momento, dedicava-se apenas à produção pecuarista. O papel desempenhado pelos açorianos no desenvolvimento econômico da região é, segundo o autor, a herança maior que eles deixaram.

Contrapondo-se às representações construídas sobre os imigrantes açorianos apresentadas até aqui, temos o depoimento de Francisco Ferreira de Souza, cirurgião-mor do $1^{\circ}$ Regimento do rio de Janeiro, que esteve no RS em 1777, e deixou registrado suas impressões sobre o lugar e o tipo humano:

Como a maior parte dos seus habitadores deste continente são insulanos ou ilhéus, os termos, os costumes, os vestuários são grosseiros, e pela mesma ordem de grosseria criam seus filhos. Esta notícia que relato não é com a intenção de satirizar costumes menos polidos de sua gente grosseira, que não tem obrigação de ser civilizada. [...] Os homens, o seu uso comum é andarem em véstia, poucos de capote, e os mais usam de um pano aberto pelo meio, a que chamem poncho, pela qual abertura mantém a cabeça, e tão bem (sic) lhes serve de cobertor na cama ou xale. Usam mais os homens de bota de pano grosso, ou picote, com os és descalços, esporas grandes e chapéu da mesma natureza, com uma fita de cor, ou preta ou rodeada a copa. As mulheres são muito grosseiras (como tão bem (sic) os homens), trazem as camisas mui (sic) sujas, e de ordinário de estopa posto que poucas de linho grosso; os corpos são mui (sic) mal feitos , só sabem falar de éguas, potrancas, cavalos, lenço, bois e bolas. As saias são de beata, e por sapatos [calçam] tamancos, por cuja razão têm os pés disformes e grandes, os dedos mal compostos, suposto que os das mãos são tão bem (sic) grosseiros, e as unhas mal sujas. Tanto os homens, como as mulheres, têm grande paixão pelo tabaco, como igualmente por uma erva chamada mate, da qual usam dela grosseiramente pisada em um porongo, ou cuia com esta bebida por almoço além de mais que dela usam em todo dia. Os meninos logo de tenra idade aprendem a laçar cachorros, quando maiores terneiros, e quando homens potros, potrancas, éguas, cavalos, quer domésticos quer xucros. A ler e escrever se não empregam, pois todo o destino é laçar, é arrear e bolear ${ }^{9}$

\footnotetext{
${ }^{8}$ LAYTANO, Dante de. Açorianos e alemães no desenvolvimento da colonização e a agricultura do Rio Grande do Sul. Porto Alegre: Livraria do Globo, 1948.

${ }^{9}$ CÉSAR, Guilhermino. Primeiros Cronistas do Rio Grande do Sul: 1605 - 1801. 3.ed. Porto Alegre: UFRGS, 1998. p. $133 / 134$.
} 
Como podemos observar, a imagem construída sobre o açoriano difere-se das demais apresentadas até o momento, uma vez que percebemos a intenção, ainda que negada, de representar o açoriano rio-grandense de forma negativa. É claro que devemos levar em consideração que se trata de uma descrição do século XVIII, realizada por um habitante do centro da Colônia que, portanto, parte da sua realidade para então analisar a situação de miséria e abandono em que viviam os açorianos no sul do Brasil. Desta forma, observamos que a forma como o imigrante açoriano é retratado nesta crônica é bastante hostil, descrevendo-os como portadores de uma cultura inferior e de hábitos nada louváveis, sendo retratado, portanto, como seres que muito se diferenciavam das demais áreas da Colônia. Foi o único momento - ainda que inserido no contexto do século XVIII em que observamos um olhar depreciativo sobre os açorianos instalados nas terras do sul do Brasil.

Contrapondo-se a essa ideia negativa dos açorianos, temos as obras do General João Borges Fortes que, sem dúvida, situa-se como um dos maiores nomes da história rio-grandense. Selecionamos duas de suas obras, que consideramos mais significativas, Troncos seculares ${ }^{10}$ e Os Casais açorianos. Presença lusa na formação sul-rio-grandense ${ }^{11}$, nas quais procuramos analisar as formas como são representados os imigrantes açorianos.

Em Troncos seculares, cuja primeira edição foi publicada no ano de 1931, o autor identifica os açorianos como responsáveis pelo povoamento e desenvolvimento do RS, salientando que estes eram pessoas de bom caráter, boa conduta e acima de tudo, muito trabalhadores. Destaca ainda em seu estudo que, os açorianos foram determinantes na defesa do território sul-rio-grandense, contra os ataques espanhóis pela conquista do Rio Grande.

Somando-se a estas feições, o autor afirma que é orgulho, descender destes imigrantes do Arquipélago, uma vez que foram estes os responsáveis por lançarem as bases para o futuro do RS. Comprovamos essas ideias com as palavras do autor:

\footnotetext{
${ }^{10}$ BORGES FORTES, João. Troncos seculares. 2.ed. Porto Alegre: Martins Livreiro Editor, 1998.

11 . Os casais açorianos. Presença lusa na formação sul-rio-grandense. 2. ed. Porto Alegre: Martins Livreiro Editor, 1978.
} 
Essa fecunda semente de uma raça forte e sadia, laboriosa e honrada, bela física e moralmente, espalhou-se pelo seio da terra que a recebia carinhosamente e fez surgirem Porto dos Casais, Taquari, Triunfo, Santo Amaro, estreito. Expandindo-se, penetrou pelas regiões interiores e com o seu denodo as foi arrebatando ao domínio castelhano. ${ }^{12}$

Soma-se à essa ideia a seguinte passagem:

São os nomes de que somos hoje portadores. Qual a família rio-grandense que, remontando aos seus antecedentes, não vai deparar nos vértices com os velhos troncos originários do Arquipélago? Qual a família que não se orgulha de provir remotamente daquela gente que todos os autores de história e sociologia, descrevem como uma raça perfeita pelas suas aprimoradas qualidades ${ }^{13}$

Na segunda obra analisada, cuja primeira edição foi publicada em 1932 com o título de Casaes, Borges Fortes confirma as suas afirmações já realizadas anteriormente em sua obra Troncos seculares. Percebemos a constante recorrência a determinados termos de forte significado para adjetivar os imigrantes açorianos, que segundo o autor eram da mais alta moral e conduta. Com isso, observamos que o autor qualifica os açorianos como sendo os grandes fundadores do RS, uma vez que foram estes que estabeleceram povoados e formaram as primeiras cidades como Taquari, Porto Alegre, Mostardas e Estreito, entre outras mais.

Outro aspecto citado na obra é a transformação étnica que os açorianos provocaram. De acordo com o autor, foram os açorianos os responsáveis por uma chamada "melhoria étnica", conforme ele próprio demonstra no trecho abaixo: " Viamo-nos, assim, libertados, quer da mácula dos degredados, quer da chaga da escravatura, com todas as suas tristes e vergonhosas consequências. Podemos os descendentes dos casais regozijar-nos dos ancestrais de nossa raça, límpida nas suas origens". ${ }^{14}$

Ainda, em conformidade com seu pensamento destacam-se as qualidades encontradas entre os imigrantes açorianos:

Os três elementos fundamentais da mais pura procedência originaram um tal tipo de raça em que se acentua sensível superioridade ao português do Reino, não só sob o aspecto das linhas exteriores do físico, como principalmente pelo lado intelectual, sendo o açoriano muito mais inteligente e laborioso do que os filhos do continente. $\mathrm{O}$ açoriano se diferencia

\footnotetext{
12 Ibidem, p. 44.

${ }^{13}$ Ibidem, p. 45.

${ }^{14}$ Ibidem, p. 16
} 
ainda pelo seu caráter pacífico, afetuoso e amável, como por sua espontânea hospitalidade e bondade de coração. Era essa gente que a metrópole escolhera para ir colonizar as terras novas que ia ganhando no sul do Brasil. Abençoado desígnio, feliz origem! ${ }^{15}$

$\mathrm{O}$ autor evidencia ainda as qualidades, tanto dos homens quanto das mulheres açorianas. Os homens são representados como trabalhadores e ordeiros, respeitadores das leis e as mulheres ótimas donas de casa, cuidadosas com seus afazeres domésticos e sendo, inclusive retratadas como santas, indicando sua conduta moral inquestionável.

Já em outro trecho da obra o autor afirma que os açorianos são "honrados, simples $e$ austeros os homens, santas e virtuosas as mulheres. Foi dos lares dessa gente que saíram as esposas que se fizeram mães dos rio-grandenses. Bendita semente, a dos açorianos! "16 E logo em seguida complementa afirmando que os açorianos são os construtores do RS, tendo em vista que são citados pelo autor como os pioneiros no processo de urbanização dessas terras do sul.

Outro autor, Rubens de Barcelos, na obra Estudos Rio-Grandenses ${ }^{17}$, cuja primeira edição data de 1955, afirma que os açorianos chegaram ao RS para exercerem seu papel de povoadores e fixarem fronteira nesta área. É visível a forma como o autor identifica os açorianos, destacando o fato de que, na verdade, apenas a terra havia mudado para os açorianos, uma vez que estes trouxeram para o Brasil todas as suas características açorianas, transplantando-as e praticando-as aqui na nova terra. Evidenciam-se ainda a boa índole do açoriano, bem como a vontade de trabalhar, representando-se assim como um povo ordeiro, trabalhador e honesto, que ao estabelecer-se nessas terras, trouxe consigo seus traços étnicos e culturais, que vieram para dar uma maior "civilidade" ao gaúcho. Conforme o autor:

Com efeito, só a terra mudava para os açoritas. Em lugar das ilhas nativas, rodeadas pelo oceano, a paisagem nova do cenário americano. Lavradores, o seu trabalho consistiria em agricultar a terra, cultivando o trigo e a vinha, como na pátria de origem. Nem a alimentação diversificava daquela a que estavam afeitos. Continuavam no novo habitat o insulamento social em que tinham vivido, conservando os mesmos hábitos, os mesmos costumes, as mesmas crenças, sob condições climatéricas semelhantes às do arquipélago. ${ }^{18}$

\footnotetext{
${ }^{15}$ Ibidem, p. 23.

${ }^{16}$ Ibidem, p. 154.

${ }^{17}$ BARCELOS, Rubens de. Estudos Rio-Grandenses. Motivos de história e literatura. 2.ed. Porto Alegre: Globo, 1960.

${ }^{18}$ Ibidem, p.13.
} 
Concordando, em grande parte, com o pensamento de Rubens de Barcelos, encontramos as palavras de Arthur Ferreira Filho. Procuramos analisar a forma como este autor refere-se aos imigrantes açorianos, buscando em sua obra "História Geral do Rio Grande do Sul (1503-1964)", cuja primeira edição foi em 1958, elementos que fazem referência a forma como Ferreira Filho interpreta os açorianos, e constrói uma imagem a seu respeito. Desta forma, observamos que o autor utiliza palavras de forte significado ao referir-se aos açorianos, enobrecendo-os e caracterizando-os como gente pacífica, bons agricultores e conhecedores de construção, dando a ideia de que estes, portanto, eram pessoas muito dadas ao trabalho e que contribuíram para a formação do RS.

Destacamos ainda a preocupação do autor em tratar das dificuldades enfrentadas pelos açorianos desde a chegada ao Brasil e que, portanto, se estes conseguiram desenvolver-se, foi em virtude da sua própria vontade de vencer, uma vez que não receberam os auxílios prometidos por parte da Coroa Portuguesa: [...] a maior parte dos imigrantes fôsse (sic) constituída de gente pacifica, bons agricultores e iniciados nas artes das construções. Sobretudo, gente de bons costumes e habituados ao trabalho. ${ }^{20}$

Logo em seguida completa seu pensamento afirmando: Os que chegaram, viram-se nos primeiros tempos a braços com dificuldades acabrunhantes - abandonados, sem recursos, saudosos da terra distante, desiludidos, sentindo falharem tôdas (sic) as promessas de seu rei. ${ }^{21} \mathrm{E}$ finalmente com o objetivo de completar sua análise afirma:

Mas a maioria, finalmente encontrou energias para se impor aos obstáculos de tôda (sic) sorte que a incúria dos governos não soubera resolver. Seus filhos já identificados com o meio, tornaram-se gaúchos, estancieiros e milicianos destemidos na defesa do solo rio-grandense. ${ }^{22}$

\footnotetext{
${ }^{19}$ FERREIRA FILHO, Arthur. História Geral do Rio Grande do Sul (1503-1964). 3. ed. Porto Alegre: Globo, 1965.

${ }^{20}$ Ibidem, p. 33.

${ }^{21}$ Ibidem, p. 33.

${ }^{22}$ Ibidem, p.34.
} 
Assim, de acordo com o autor, os açorianos trouxeram a sua vontade de conquistar e desenvolver a nova terra ocupada, mesmo com todos os contratempos causados pelo descaso da Coroa para com eles. Percebemos, nas palavras do autor, o claro objetivo do autor em recriar uma imagem gloriosa para os açorianos, que venceram, mesmo em meio a todos os obstáculos enfrentados.

\section{CONSIDERAÇÕES FINAIS}

Percorremos parte da produção historiográfica existente sobre a imigração açoriana no RS, em especial aquelas consideradas clássicas pela historiografia. Através dele foi possível estabelecer um forte vínculo entre a difusão das ideias positivas sobre os imigrantes nas obras analisadas e seus autores. Isso se deve, principalmente, pelos laços étnicos que identificam esses autores ao tema de suas análises.

Observa-se, entretanto, que a única visão detratora dos açorianos é apresentada pelo militar do século XVIII, que os descreveu a partir do olhar eurocêntrico. Nas demais interpretações, os açorianos aparecem como elemento civilizador e responsável pelo início do desenvolvimento social e econômico do RS. Conclui-se, portanto, que as diferentes interpretações construídas pelos diferentes autores nessas obras são, antes de mais nada, o resultado da idealização de um imigrante ímpar e responsável pela argamassa étnica que constituiria mais tarde a sociedade rio-grandense.

\section{REFERÊNCIAS BIBLIOGRÁFICAS}

ANAIS da II Semana de Estudos Açorianos. Florianópolis: UFSC, 1989.

BARBOSA, Fidélis D. História do Rio Grande do Sul. 3.ed. Porto Alegre: Escola Superior de Teologia São Lourenço de Brindes/Martins Livreiro, 1985. 
BARCELOS, Rubens de. Estudos Rio-Grandenses. Motivos de história e literatura. 2.ed. Porto Alegre: Globo, 1965.

BORGES FORTES, J. Os casais açorianos. Presença lusa na formação sul-rio-grandense. 2. Ed. Porto Alegre: Martins Livreiro, 1978.

. Troncos seculares. 2.ed. Porto Alegre: Martins Livreiro, 1998.

CÉSAR, Guilhermino. Primeiros Cronistas do Rio Grande do Sul: 1605 - 1801. 3.ed. Porto Alegre: UFRGS, 1998.

FERREIRA FILHO, Arthur. História Geral do Rio Grande do Sul (1503-1964). 3. ed. Porto Alegre: Globo, 1965.

LAYTANO, Dante de. Açorianos e Alemães no Desenvolvimento da Colonização e Agricultura do Rio Grande do Sul. Porto Alegre: Globo, 1948.

SANTOS, Corcino M. dos. Economia e sociedade do Rio Grande do Sul. Século XVIII. São Paulo: Editora Nacional, 1984.

WIEDERSPAHN, Oscar H. A colonização açoriana no Rio Grande do Sul. Porto Alegre: Escola Superior de Teologia São Lourenço de Brindes/Instituto Cultural Português, 1979. 